\title{
Improved waitlist and transplant outcomes for pediatric lung transplantation after implementation of the lung allocation score
}

\author{
Timothy S. Lancaster, MDa, Jacob R. Miller, MDa, Deirdre J. Epstein, RN ${ }^{\mathrm{a}}$, Nicholas C. \\ DuPont, MS ${ }^{a}$, Stuart C. Sweet, MD ${ }^{b}$, Pirooz Eghtesady, MD, PhD ${ }^{a}$ \\ aSection of Pediatric Cardiothoracic Surgery, Washington University School of Medicine, St. Louis \\ Children's Hospital, St. Louis, Missouri, USA; \\ bDivision of Pediatric Allergy, Immunology and Pulmonary Medicine, Washington University \\ School of Medicine, St. Louis Children's Hospital, St. Louis, Missouri, USA.
}

\section{Abstract}

BACKGROUND: Although the lung allocation score (LAS) has not been considered valid for lung allocation to children, several additional policy changes for pediatric lung allocation have been adopted since its implementation. We compared changes in waitlist and transplant outcomes for pediatric and adult lung transplant candidates since LAS implementation.

METHODS: The United Network for Organ Sharing database was reviewed for all lung transplant listings during the period 1995 to June 2014. Outcomes were analyzed based on date of listing (pre-LAS vs post-LAS) and candidate age at listing (adults > 18 years, adolescents 12 to 17 years, children 0 to 11 years).

RESULTS: Of the 39,962 total listings, 2,096 (5\%) were for pediatric candidates. Median waiting time decreased after LAS implementation for all age groups (adults: 379 vs 83 days; adolescents: 414 vs 104 days; children: 211 vs 109 days; $p<0.001$ ). The proportion of candidates reaching transplant increased after LAS (adults: $52.6 \%$ vs $71.6 \%, p<0.001$; adolescents: $40.3 \%$ vs $61.6 \%$, $p<0.001$; children: $42.4 \%$ vs $50.9 \%, p=0.014$ ), whereas deaths on the waitlist decreased (adults: $28.0 \%$ vs $14.4 \%, p<0.001$; adolescents: $33.1 \%$ vs $20.9 \%, p<0.001$; children: $32.2 \%$ vs $25.0 \%$; $p$ $=0.025)$, despite more critically ill candidates in all groups. Median recipient survival increased after LAS for adults and children (adults: 5.1 vs 5.5 years, $p<0.001$; children: 6.5 vs 7.6 years, $p$ $=0.047$ ), but not for adolescents ( 3.6 vs 4.3 years, $p=0.295$ ).

CONCLUSIONS: Improvements in waiting time, mortality and post-transplant survival have occurred in children after LAS implementation. Continued refinement of urgency-based allocation to children and broader sharing of pediatric donor lungs may help to maximize these benefits.

\section{Keywords}

pediatric; children; outcomes; lung transplantation; lung allocation score

Reprint requests: Pirooz Eghtesady, MD, PhD, Section of Pediatric Cardiothoracic Surgery, Washington University School of Medicine, St. Louis Children's Hospital, One Children's Place, Suite 5 South, St. Louis, MO63110.Telephone +314-454-6165.Fax: +314-454-2381, eghtesadyp@wudosis.wustl.edu.

Supplementary materials

Supplementary data associated with this article can be found in the online version at www.jhltonline.org. 
The lung allocation score (LAS) was implemented in May 2005 for lung transplant candidates $\geq 12$ years of age, with the purpose of shifting donor lung allocation policy from a system based on accumulated waiting time to a system based on medical urgency. To this end, the LAS is a composite score, based on 2 risk-prediction models, which prioritizes allocation to candidates with a high probability of waitlist mortality balanced with an acceptable probability of 1-year post-transplant survival. ${ }^{1,2}$ In adolescents and adults, allocation based on the LAS has resulted in decreased waiting time and waitlist deaths and increased transplant rates, as well as increased transplantation of older candidates, those with fibrotic lung disease, and more critically ill candidates with higher LASs. ${ }^{3-7}$ Despite prioritization of candidates with higher medical urgency for transplant, an improvement in overall 1-year post-transplant survival has been observed, ${ }^{3}$ although others have reported inferior post-transplant survival in recipients with higher LASs. ${ }^{4,7-9}$

The LAS has not been considered valid for pediatric candidates $<12$ years of age, however, primarily because differences in diagnoses between children and older candidates made the mortality risk prediction model of the LAS inappropriate as a measure of medical urgency. In addition, the small numbers of lung transplant recipients in this age group have not allowed for the creation of a reliable post-transplant survival model for children. ${ }^{1,10,11}$

Although the LAS has not been used in children $<12$ years old, several other key changes have occurred in lung allocation policy for this age group since LAS inception. These include adoption of broader geographic sharing for prioritized allocation of child donor lungs to child candidates, ${ }^{12}$ creation of a 2-tier priority system for stratification of child candidates based on medical urgency, ${ }^{12}$ and approval of an adolescent exception policy to allow individual child candidates to participate in the LAS system under special circumstances. ${ }^{13}$ The applicability of a medical urgency-based allocation policy to children has been debated widely, ${ }^{10,14-21}$ but corollaries to the marked changes in adult allocation and transplant outcomes since LAS inception have not been thoroughly examined in the pediatric population. One study suggested that, although transplant rates rose similarly after LAS implementation in candidates aged $<12$ and $\geq 12$ years, the rise in waitlist death rates may have been greater in candidates aged $<12$ years. ${ }^{22}$ We therefore sought to examine the changes in waitlist and transplant outcomes for pediatric lung transplant candidates since implementation of the LAS.

\section{Methods}

\section{Study population}

This study was approved by the institutional review board of Washington University School of Medicine. Standard Transplant Analysis and Research (STAR) data files were reviewed for all waitlist entries for lung transplantation included in the Organ Procurement and Transplantation Network (OPTN)/United Network for Organ Sharing (UNOS) database from 1995 to June 31, 2014. Patients receiving heart-lung or living donor lung transplantation were excluded. To minimize the contribution of an "era effect" to differences in outcomes, candidates listed before 1995 were excluded. ${ }^{23,24}$ 
The LAS was implemented on May 4, 2005 and, accordingly, listings were divided into 2 cohorts based on date of listing: pre-LAS (January 1, 1995 to May 3, 2005) and post-LAS (May 4, 2005 to June 31, 2014). Based on candidate age at listing, the listings were then sub-divided into age groups consistent with those used in OPTN lung allocation policies: adults ( $\geq 18$ years); adolescents (12 to 17 years); and children (0 to 11 years). ${ }^{2}$

\section{Study outcomes}

LASs for all candidates listed after May 4, 2005, including candidates $<12$ years of age, were used as provided from calculated fields in the STAR data files. Priority status data for child candidates listed after January 1, 2010 was obtained by special request from OPTN/ UNOS.

A waitlist analysis was conducted, which included all waitlist entries for the study cohort and compared group characteristics at the time of listing and waitlist outcomes. Waitlist mortality and transplant rates were calculated as the number of deaths or transplants, respectively, per 100 patient-years on the waitlist, and are reported by year of candidate listing. A waitlist outcome of "too sick to transplant" was considered a mortality for this analysis.

A transplant analysis was also conducted, which included all deceased donor lung transplantations for the study cohort and compared group characteristics at the time of transplant, as well as long-term post-transplant survival. Survival data for this analysis were used as provided in the STAR data files and are current as of the end of the study period.

\section{Statistical analysis}

Continuous variables were expressed as mean \pm standard deviation or as median with interquartile range, and were compared using either $t$-tests for 2-sample comparisons or 1way analysis of variance with post-hoc analysis by Tukey's method for multiple comparisons. Categorical variables were expressed as frequencies and percentages, and were compared using chi-square analysis with Bonferroni's correction for multiple a priori comparisons. Kaplan-Meier survival curves for post-transplant survival were constructed, and were compared using the log-rank test. Data analyses were performed using SAS version 9 (SAS Institute, Cary, NC) and SPSS version 23.0 (IBM SPSS, Armonk, NY) statistical software.

\section{Results}

\section{Waitlist analysis}

A total of 39,962 listings were included in the waitlist analysis. Of these, 2,096 (5.2\%) were for pediatric candidates $<18$ years of age. Mean LASs are presented for all candidates listed after May 4, 2005, although LAS was not used for allocation in children. Mean LASs were lower in children than adolescents and adults at both listing and waitlist removal, although a similar gradual rise was seen in all groups throughout the post-LAS time period (Figure 1A). Priority classification is presented for children listed after January 1, 2010 (Table 1). 
Notable differences in diagnosis groupings included a higher prevalence of pulmonary vascular disease (Group B, includes most listings for congenital heart disease) and restrictive/interstitial lung disease (Group D), and a lower prevalence of cystic fibrosis/ immunodeficiencies (Group C) in children compared with adolescents (see Table S1 in Supplementary Material, available online at www.jhltonline.org). There was little change in diagnosis groupings after LAS implementation for children and adolescents, as opposed to adults, in whom there was a decrease in the prevalence of Groups A, B and C with a concomitant rise in Group D (Table 1).

The degree of critical illness in children far exceeded that of adolescents and adults in both the pre-LAS and post-LAS time periods, with a higher requirement for any life support and mechanical ventilation at listing in children (see Table S1 in Supplementary Material). The degree of critical illness at listing increased for adolescents and adults after LAS implementation, but with a higher requirement for any life support, mechanical ventilation, extracorporeal membrane oxygenation (ECMO) and inhaled nitric oxide (NO) in the postLAS groups (Table 1). Changes in the degree of critical illness after LAS implementation were not as substantial in children as they were in adolescents, although the proportion of children requiring mechanical ventilation and hospitalization at the time of transplant did increase (Table 2).

Median waiting times decreased markedly after LAS implementation for all age groups (Table 1 and Figure 1B). The proportion of listed candidates reaching transplantation was higher after LAS implementation for all age groups (Table 1 and Figure 2A), and the transplant rate similarly increased (Table 1 and Figure 2B). The proportion of listed candidates who died on the waitlist was lower after LAS implementation for all age groups (Table 1 and Figure 3A), but waitlist mortality increased for both adolescents and children (Table 1 and Figure 3B).

\section{Transplantation and survival analysis}

A total of 24,584 deceased donor lung transplantations were included in the transplantation analysis. Of these, 987 (4.0\%) were for pediatric candidates. As with LASs at listing, mean LASs at transplant were lower in children than in adolescents and adults. Priority status classification at transplant is presented in Table 2 for children listed after January 1, 2010.

Similar to the waitlist analysis, the degree of critical illness at transplant was higher for children than for adults and adolescents in both the pre-LAS and post-LAS time periods. Measures of critical illness at transplant increased for all groups after LAS implementation, including increases in any life support, mechanical ventilation, ECMO, inhaled NO, hospitalization and intensive care unit stay (Table 2).

Median post-transplant survival increased after LAS implementation for both adults (5.1 years pre-LAS vs 5.5 years post-LAS, $p<0.001$; Figure 4 A) and children (6.5 vs 7.6 years, $p=0.047$; Figure 4 C), but did not change for adolescents (3.6 vs 4.3 years, $p=0.295$; Figure 4B). In the post-LAS cohorts, median survival was higher for children than for both adults ( 7.6 vs 5.5 years, respectively, $p=0.029$ ) and adolescents ( 7.6 vs 4.3 years, $p=0.006$; 
Figure 4D). There was also a trend toward higher median survival in adults compared with adolescents in the post-LAS time period (5.5 vs 4.3 years, $p=0.093$; Figure 4D).

\section{Discussion}

In this study, changes in waitlist and transplant outcomes after implementation of the lung allocation score were examined for pediatric and adult lung transplant candidates. Key findings of the study were: (1) LASs were lower in children than adolescents and adults, despite a greater requirement for life support and a higher proportion of waitlist deaths in child candidates; (2) requirements for life support and hospitalization increased for candidates of all age groups after LAS implementation; (3) waitlist outcomes, including waiting times, transplant rates and waitlist mortality, improved for all age groups, although the magnitude of benefit was less for children compared with adolescents and adults; and (4) post-transplant survival improved after LAS implementation for adults and children, but it did not change for adolescents.

The discrepancy between lower mean LASs and higher rates of life support, hospitalization and waitlist deaths in children suggests that the LAS under-represents the degree of critical illness for child candidates, a finding that is not unexpected. The LAS was not developed to be used in child candidates and their data were not included in its risk-prediction models. ${ }^{1}$ Therefore, the LAS models may not appropriately weigh the mortality risk of certain variables that have unique significance in pediatric patients. For example, children suffer from different diseases than adults, and certain pediatric diagnoses may carry a disproportionately higher risk of mortality than others in the same diagnosis grouping. . $^{1,25,26}$ Further, the LAS includes several variables that are not commonly obtained or are difficult to obtain in children, such as forced vital capacity and 6-minute walk test. Default values are substituted for missing data in the LAS calculation, which may result in a LAS that does not accurately reflect the severity of illness of a child candidate. The OPTN/UNOS Lung Review Board recently affirmed that the LAS is inappropriate for widespread use in children, ${ }^{26}$ although the adolescent exception policy does allow older children to be considered for inclusion in the LAS system when appropriate. ${ }^{13}$

Despite the fact that the LAS is not applicable for use in children, we demonstrated in this study that changes in outcomes for child lung transplant candidates have largely mirrored those of their adolescent and adult counterparts since LAS inception. Consistent with the intent of the LAS to prioritize candidates with higher risk of waitlist mortality, candidates of all age groups were more critically ill after LAS implementation, as represented by higher proportions of mechanical ventilation, ECMO and other forms of life support, either at listing or transplant. The proportion of patients hospitalized at the time of transplant also increased for all age groups (Tables 1 and 2).

Marked improvements in median waiting times and transplant rates were observed for all age groups in the post-LAS time period. When depicted over time (Figures 1B and 2B), these changes clearly coincide with implementation of the LAS in 2005. Although similar findings have been well established for adolescent and adult candidates, 3,4 they are 
especially intriguing for children given that the LAS did not directly alter lung allocation policy for this group.

The proportion of deaths on the waitlist decreased for all age groups after LAS implementation (Figure 3A), although, perhaps counterintuitively, waitlist mortality rates increased in child and adolescent candidates over the same period (Figure 3B). This comparison highlights the important point that waitlist mortality rates are dependent on changes in waiting time, which is incorporated into the denominator of the mortality rate calculation. Care should be taken to avoid interpreting this increase in waitlist mortality rates as an actual increase in waitlist deaths for pediatric candidates.

Long-term post-transplant survival was improved for child and adult recipients listed after LAS implementation, yet it was unchanged for adolescent recipients (Figure 4). The effect of the LAS on post-transplant survival cannot be completely distinguished from overall trends of increasing post-transplant survival over time, ${ }^{27,28}$ and earlier reports of its effect have differed based on the duration of follow-up and the specific cohorts compared. ${ }^{3,29}$ It is notable, however, that, in this study, long-term survival was not diminished in any age group despite a higher degree of critical illness at transplant. The combination of reduced waitlist deaths, improved transplant rates and unchanged or improved post-transplant survival suggests an overall net benefit for all age groups in the post-LAS era. The survival advantage for children compared with adolescents and adults in the current era (Figure 4D) is consistent with other reports and historic trends. ${ }^{30,31}$

Although causation cannot be definitively determined from these data, the altered outcomes for children occurring in the absence of the LAS are likely attributable to several other modifications to pediatric lung allocation policy since LAS inception. The earliest of these efforts was the Organ Donation Breakthrough Collaboratives, established by the Health Resources and Services Administration, which began in 2003 and resulted in increased donor availability for candidates of all ages. ${ }^{3,32}$ Subsequent policy changes developed specifically for pediatric lung allocation included broader geographic sharing for prioritized allocation of child donor lungs to child candidates and a 2-tier priority system for stratification of child candidates based on medical urgency, both implemented in 2010. ${ }^{12}$ Although likely having little impact on this study cohort, an adolescent exception policy was also implemented in 2013, allowing individual child candidates to participate in the LAS system when appropriate. ${ }^{13}$ Finally, indirect effects of the LAS itself may have contributed to altered outcomes for children, perhaps by provoking a shift in listing practices and adoption of an urgency-based prioritization philosophy resulting from practitioner experience with the LAS in older candidates.

Despite these many policy advancements for pediatric candidates, the improvements in waitlist outcomes for children were smaller in magnitude than those seen with formal LAS implementation in adults and adolescents. For example, the proportion of patients transplanted after LAS increased by $19 \%$ in adults and $21.3 \%$ in adolescents, but only $8.5 \%$ in children. Waitlist deaths decreased by $13.6 \%$ in adults and by $12.2 \%$ in adolescents, yet by only $7.2 \%$ in children. In addition, children still had the highest proportion of waitlist deaths of all age groups ( $25 \%$ of listed child candidates) (Table 1). Potential explanations for 
the discrepantly high waitlist mortality in child lung transplant candidates have been examined recently by other groups. For example, shorter height was independently associated with waitlist mortality for both overall and child transplant candidates, suggesting that the incorporation of this variable could improve the performance of the LAS and help reduce waitlist mortality, especially for children. ${ }^{33,34}$ Ongoing refinement of the prioritization system may further improve waitlist outcomes, although an LAS-like scoring system may still be inappropriate for children, as discussed earlier.

Increasing the number of donor lungs available to listed candidates is potentially an even more effective approach to improve waitlist outcomes for children. In contrast to adults, there are adequate numbers of pediatric donors for the number of listed pediatric lung transplant candidates, but lung donation rates from these donors remain low. ${ }^{10}$ This discrepancy likely results from the requirement for size-matching in pediatric recipients and from inadequate allocation of available pediatric organs, but recent analyses have concluded that broader geographic sharing of all pediatric donor lungs may help address the problem. 3,10,26,35 As a result, the OPTN/UNOS Board of Directors recently approved expanded geographic sharing to direct all lungs from pediatric donors $<18$ years old to child candidates $<12$ years old first within a 1,000-mile radius. ${ }^{26,36}$ This policy seeks to maximize the availability of appropriately sized pediatric donor organs to pediatric candidates, and may especially benefit older children nearing age 12 who could accommodate lungs from smaller adolescent donors. The new policy change provides for broader sharing and also for ABO-incompatible transplants in children listed before their second birthday. ${ }^{26}$ Additional means of broadening the pediatric lung donor pool include more aggressive management of potential pediatric donors as well as incorporation of emerging techniques and technologies to facilitate evaluation and potential use of more marginal donors (such as donation after cardiac death and ex-vivo lung perfusion). Incorporation of these new policies and practices will likely expand upon the improved outcomes demonstrated here for both child and adolescent lung transplant candidates.

\section{Limitations}

As with any retrospective database review, we could not definitively determine causation for the altered outcomes described in this study, as it was impossible to control for advances in medical care over time that may have contributed. The pre-LAS time period was limited to listings after 1995 to reduce the impact of an "era effect," although it cannot be completely removed.

In addition, because LAS was not actively used for matching in child candidates, missing data for the input LAS variables may have contributed to the overall lower calculated LASs for child candidates. Unfortunately, we were unable to determine the extent of missing input data for the LAS fields.

Finally, organ allocation policies work in large part by limiting the placement of patients on the waitlist. ${ }^{37}$ Because the OPTN/UNOS database includes data only on listed candidates, we were unable to analyze whether care was improved for the entire pool of patients who could benefit from transplantation. 


\section{Supplementary Material}

Refer to Web version on PubMed Central for supplementary material.

\section{Disclosure statement}

The authors have no conflicts of interest to disclose. The content is the responsibility of the authors alone and does not necessarily reflect the views or policies of the U.S. Department of Health and Human Services, nor does mention of trade names, commercial products or organizations imply endorsement by the U.S. Government. This study was supported by the National Institutes of Health (Grant T32-HL-007776-19 to T.S.L.) and by the Health Resources and Services Administration (Contract 234-2005-37011C). These study findings were part of an oral presentation at the 37th annual meeting of the International Society for Heart and Lung Transplantation, Washington, DC, April 2016.

\section{References}

1. Egan TM, Murray S, Bustami RT, et al. Development of the new lung allocation system in the United States. Am J Transplant 2006;6:1212-27. [PubMed: 16613597]

2. Organ Procurement and Transplantation Network. OPTN Policy 10: Allocation of lungs Washington, DC: Department of Health and Human Services; 125-52 https:// optn.transplant.hrsa.gov/media/1200/optn_policies.pdf/.

3. Egan TM, Edwards LB. Effect of the lung allocation score on lung transplantation in the United States. J Heart Lung Transplant 2016;35:433-9. [PubMed: 26922274]

4. McShane PJ, Garrity ER Jr.. Impact of the lung allocation score. Semin Respir Crit Care Med 2013;34:275-80. [PubMed: 23821502]

5. Yusen RD, Shearon TH, Qian Y, et al. Lung transplantation in the United States, 1999-2008. Am J Transplant 2010;10:1047-68. [PubMed: 20420652]

6. Hachem RR, Trulock EP. The new lung allocation system and its impact on waitlist characteristics and post-transplant outcomes. Semin Thorac Cardiovasc Surg 2008;20:139-42. [PubMed: 18707648]

7. Valapour M, Skeans MA, Heubner BM, et al. OPTN/SRTR 2013 Annual Data Report: Lung. Am J Transplant 2015;15(suppl 2):1-28. [PubMed: 25626342]

8. Merlo CA, Weiss ES, Orens JB, et al. Impact of U.S. lung allocation score on survival after lung transplantation. J Heart Lung Transplant 2009;28:769-75. [PubMed: 19632571]

9. Hayanga JA, Lira A, Vlahu T, et al. Lung transplantation in patients with high lung allocation scores in the US: evidence for the need to evaluate score specific outcomes. J Transplant 2015;2015:836751. [PubMed: 26798504]

10. Egan TM, Sweet SC. Rationing lung transplants. N Engl J Med 2013;369:2064-5. [PubMed: 24256395]

11. Colvin-Adams M, Valapour M, Hertz M, et al. Lung and heart allocation in the United States. Am J Transplant 2012;12:3213-34. [PubMed: 22974276]

12. Procurement Organ and Network Transplantation. Summary of actions of the OPTN/UNOS Board of Directors. 6 23, 2009 https://optn.transplant.hrsa.gov/SharedContentDocuments/ 2009JulyPolicyNotice.pdf/. Accessed April 20, 2016.

13. Procurement Organ and Network Transplantation. Summary of actions of the OPTN/UNOS Board of Directors. 7 1, 2014 https://optn.transplant.hrsa.gov/ContentDocuments/ OPTN_Policy_Notice_07-01-2014.pdf/. Accessed April 20, 2016.

14. Sweet SC, Barr ML. Pediatric lung allocation: the rest of the story. Am J Transplant 2014;14:11-2.

15. deSante J, Caplan A, Hippen B, et al. Was Sarah Murnaghan treated justly? Pediatrics 2014;134:155-62. [PubMed: 24918227]

16. Mallory GB. Pursuing distributive justice in pediatric lung transplantation. Pediatr Transplant 2015;19:249-51. [PubMed: 25808911]

17. Halpern SD. Turning wrong into right: the 2013 lung allocation controversy. Ann Intern Med 2013;159:358-9. [PubMed: 23797998] 
18. Harvey SG. The 2013 lung allocation controversy. Ann Intern Med 2013;159:794.

19. Halpern SD. The 2013 lung allocation controversy. Ann Intern Med 2013;159:794-.

20. Ladin K, Hanto DW. Rationing lung transplants-procedural fairness in allocation and appeals. N Engl J Med 2013;369:599-01. [PubMed: 23883330]

21. Ladin K, Hanto DW. Rationing lung transplants. N Engl J Med 2013; 369:2065-6. [PubMed: 24256394]

22. Snyder JJ, Salkowski N, Skeans M, et al. The equitable allocation of deceased donor lungs for transplant in children in the United States. Am J Transplant 2014;14:178-83. [PubMed: 24330259]

23. Yusen RD, Edwards LB, Kucheryavaya AY, et al. The Registry of the International Society for Heart and Lung Transplantation: thirty-first adult lung and heart-lung transplant report-2014; Focus theme: retransplantation. J Heart Lung Transplant 2014;33:1009-24. [PubMed: 25242125]

24. Benden C, Goldfarb SB, Edwards LB, et al. The Registry of the International Society for Heart and Lung Transplantation: seventeenth official pediatric lung and heart-lung transplantation report2014; Focus theme: retransplantation. J Heart Lung Transplant 2014;33: 1025-33. [PubMed: 25242126]

25. Kirkby S, Hayes D Jr. Pediatric lung transplantation: indications and outcomes. J Thorac Dis 2014;6:1024-31. [PubMed: 25132969]

26. Procurement Organ and Network Transplantation. OPTN/UNOS Public Comment Proposal: Proposal to Modify Pediatric Lung Allocation Policy. 8 14, 2015 https://optn.transplant.hrsa.gov/ media/1190/0815-10_Ped_Lung_Allocation.pdf/. Accessed April 20, 2016.

27. Yusen RD, Christie JD, Edwards LB, et al. The Registry of the International Society for Heart and Lung Transplantation: thirtieth adult lung and heart-lung transplant report-2013; Focus theme: age. J Heart Lung Transplant 2013;32:965-78. [PubMed: 24054805]

28. Benden C, Edwards LB, Kucheryavaya AY, et al. The Registry of the International Society for Heart and Lung Transplantation: sixteenth official pediatric lung and heart-lung transplantation report-2013; Focus theme: age. J Heart Lung Transplant 2013;32:989-97. [PubMed: 24054807]

29. Maxwell BG, Levitt JE, Goldstein BA, et al. Impact of the lung allocation score on survival beyond 1 year. Am J Transplant 2014;14: 2288-94. [PubMed: 25208599]

30. Magee JC, Krishnan SM, Benfield MR, et al. Pediatric transplantation in the United States, 19972006. Am J Transplant 2008;8:935-45. [PubMed: 18336697]

31. Hayes D Jr, Benden C, Sweet SC, et al. Current state of pediatric lung transplantation. Lung 2015;193:629-37. [PubMed: 26238859]

32. Shafer TJ, Wagner D, Chessare J, et al. Organ donation breakthrough collaborative: increasing organ donation through system redesign. Crit Care Nurse 2006;26:33-42, 4-8; quiz 9. [PubMed: 16565280]

33. Keeshan BC, Rossano JW, Beck N, et al. Lung transplant waitlist mortality: height as a predictor of poor outcomes. Pediatr Transplant 2015;19:294-300. [PubMed: 25406495]

34. Sell JL, Bacchetta M, Goldfarb SB, et al. Short stature and access to lung transplantation in the United States. a cohort study. Am J Respir Crit Care Med 2016;193:681-8. [PubMed: 26554631]

35. Tsuang WM, Chan KM, Skeans MA, et al. broader geographic sharing of pediatric donor lungs improves pediatric access to transplant. Am J Transplant 2016;16:930-7. [PubMed: 26523747]

36. Procurement Organ and Network Transplantation. Summary of actions of the OPTN/UNOS Board of Directors. 12 23, 2015 https://optn.transplant.hrsa.gov/media/1224/policy_notice_12-2015.pdf/. Accessed April 20, 2016.

37. Halpern SD. Beyond "the LAS is broken." Ways to improve lung allocation. Am J Respir Crit Care Med 2015;191:245-6. [PubMed: 25635485] 

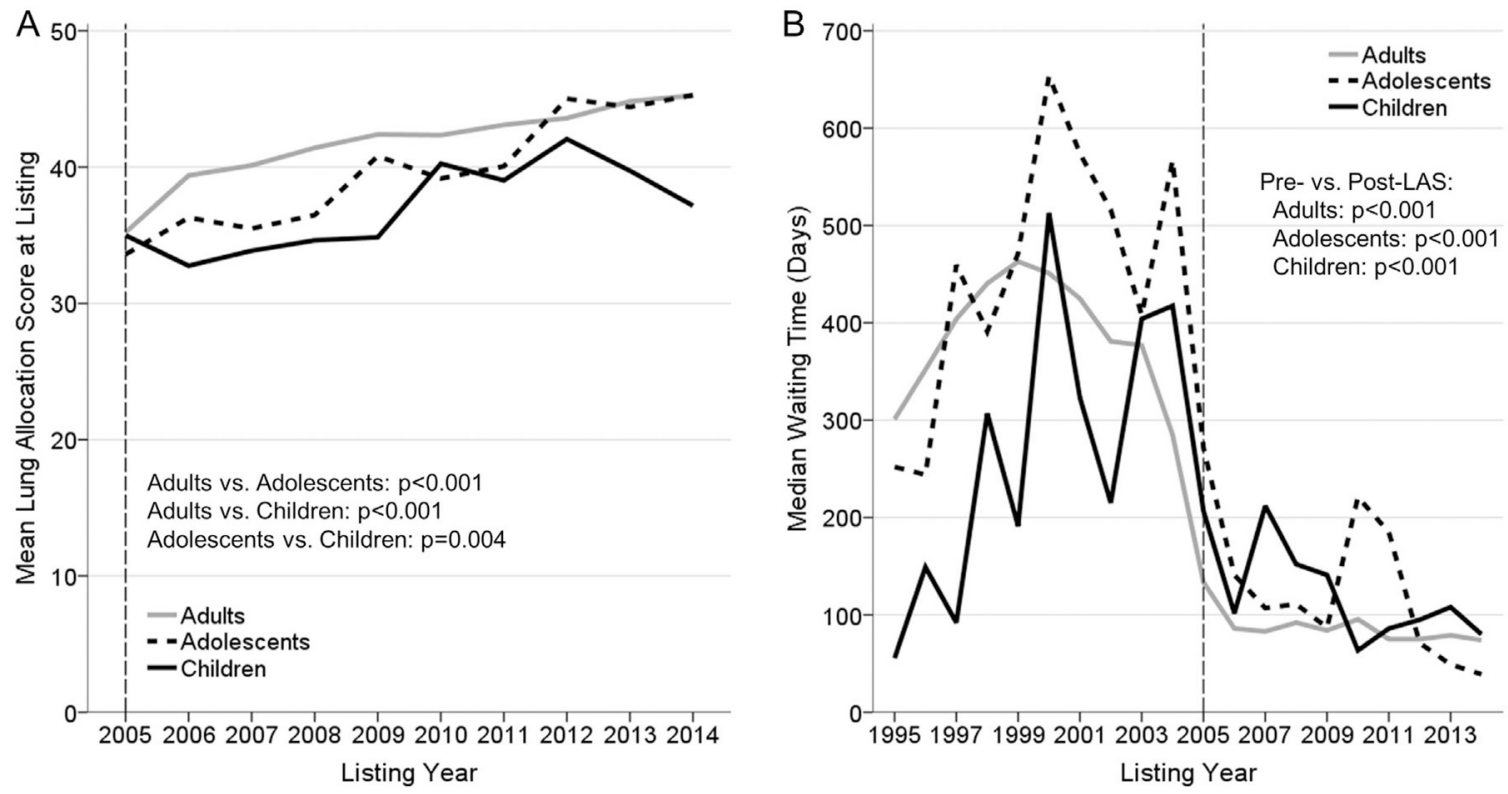

Figure 1.

(A) Mean lung allocation scores at listing and (B) median waiting times for adults, adolescents and children listed for lung transplantation, by year of candidate listing. Dashed line represents year of implementation lung allocation score (LAS). 

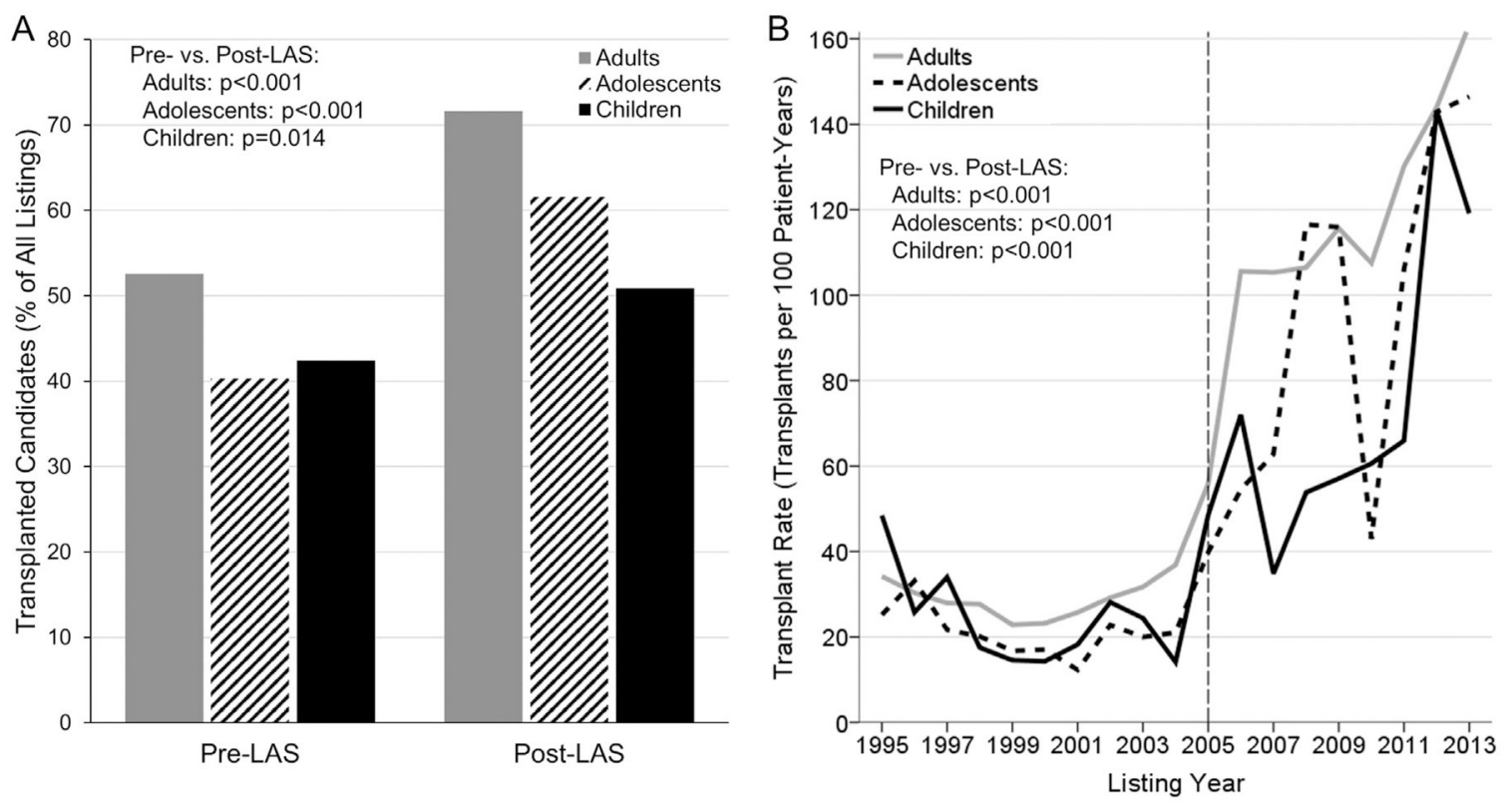

Figure 2.

(A) Proportion of listed candidates reaching transplantation before and after LAS implementation, by candidate age group.(B) Annual transplant rate (mean annual transplants per 100 patient-years on waitlist) by year of listing and candidate age group. Dashed line represents year of implementation of lung allocation score (LAS). 

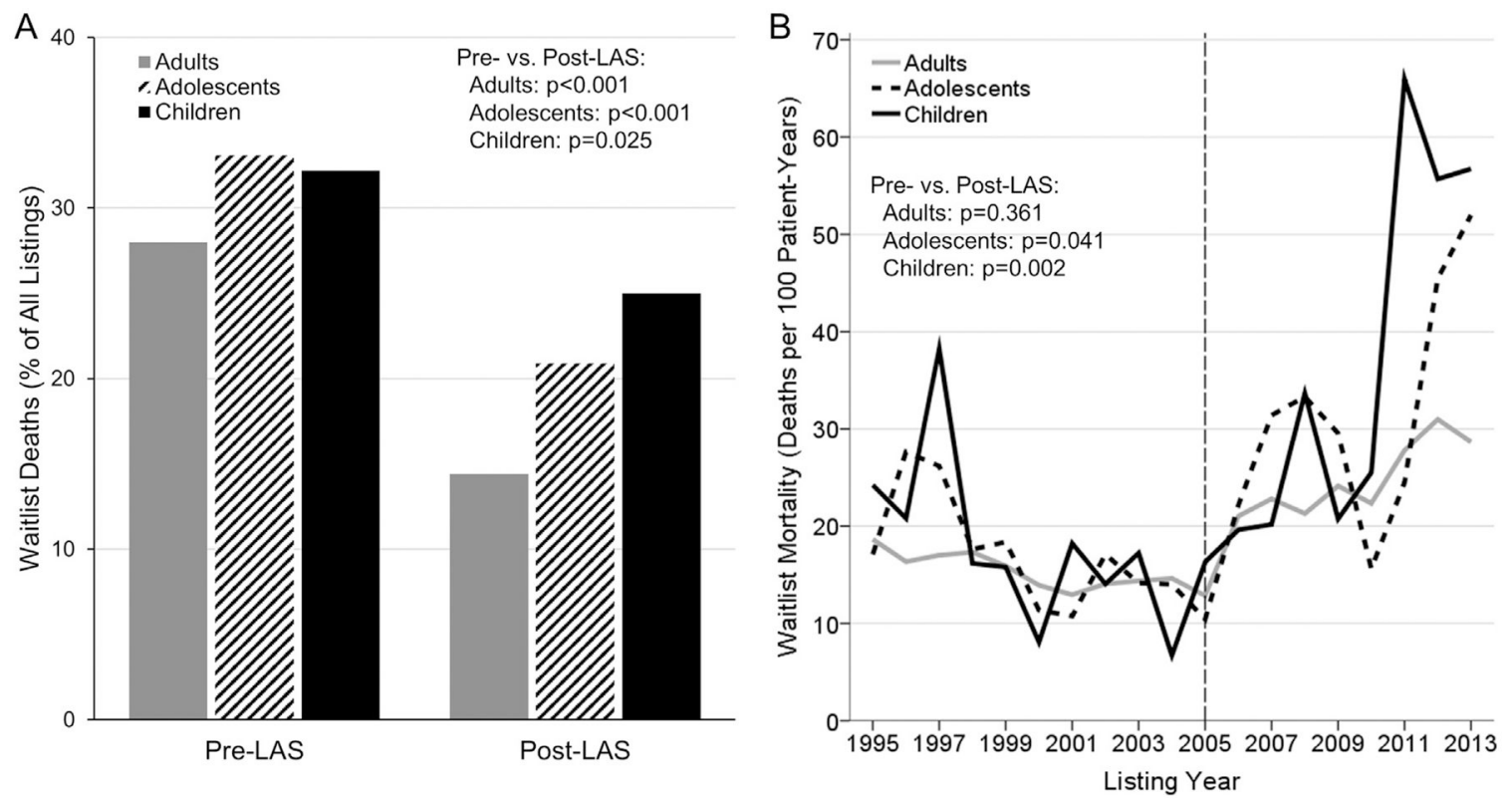

Figure 3.

(A) Proportion of waitlist deaths before and after LAS implementation, by candidate age group. (B) Annual waitlist mortality rate (mean annual waitlist deaths per 100 patient-years on waitlist) by year of listing and candidate age group. Waitlist death included waitlist removals for both death and "too sick to transplant." Dashed line represents year of implementation of lung allocation score (LAS). 

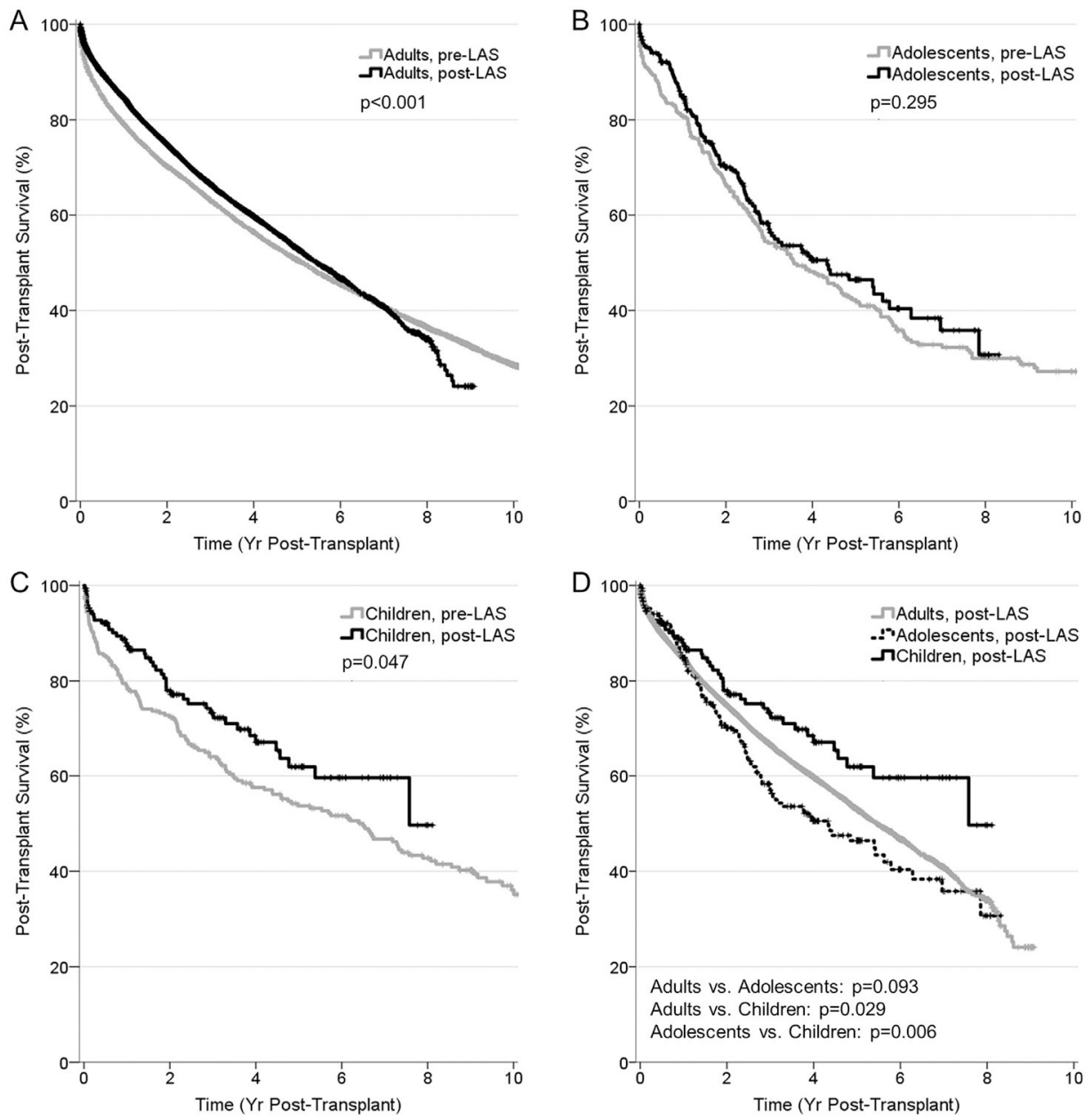

Figure 4.

Kaplan-Meier analysis of post-transplant survival for (A) adults, (B) adolescents and (C) children listed before or after LAS implementation. (D) Comparison of post-transplant survival for adults, adolescents and children listed after implementation of the lung allocation score (LAS). 


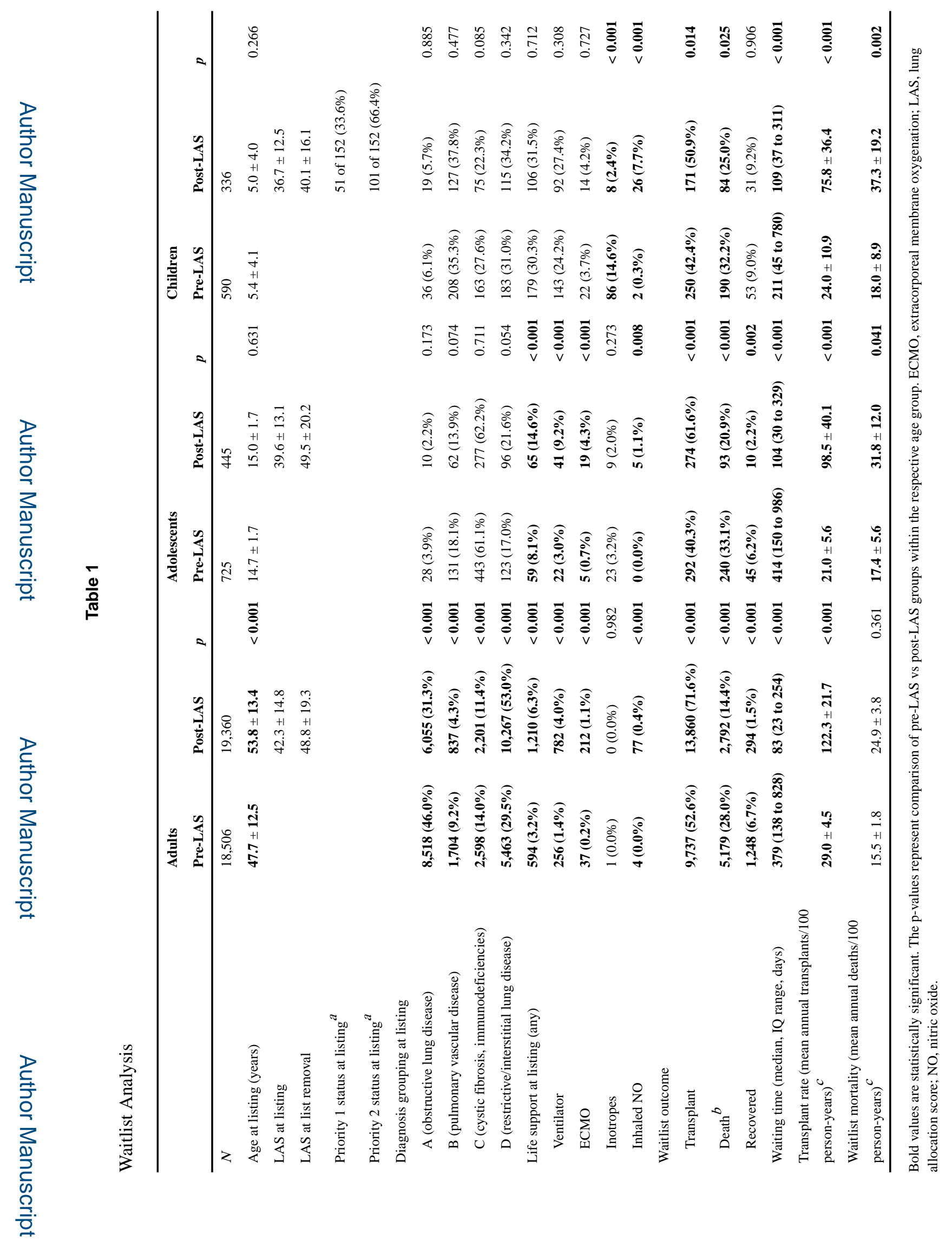

J Heart Lung Transplant. Author manuscript; available in PMC 2020 January 02. 

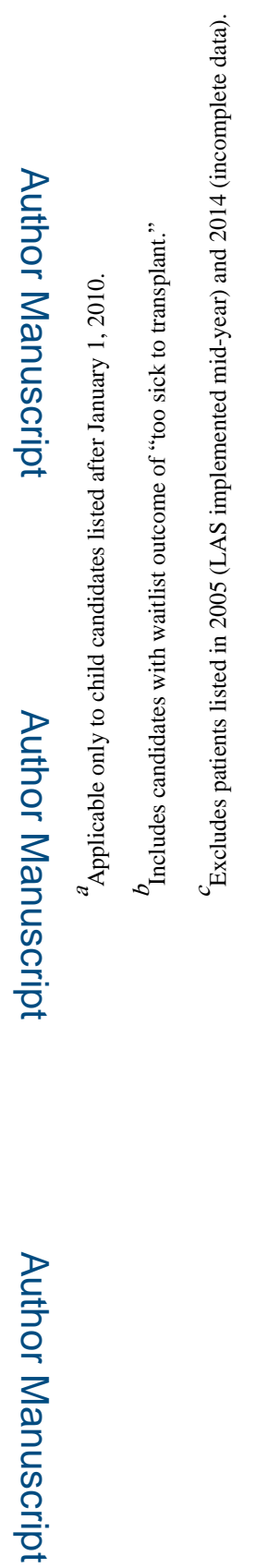

를

J Heart Lung Transplant. Author manuscript; available in PMC 2020 January 02. 


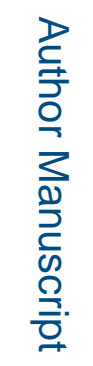

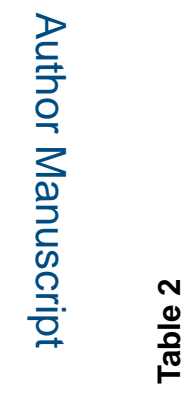

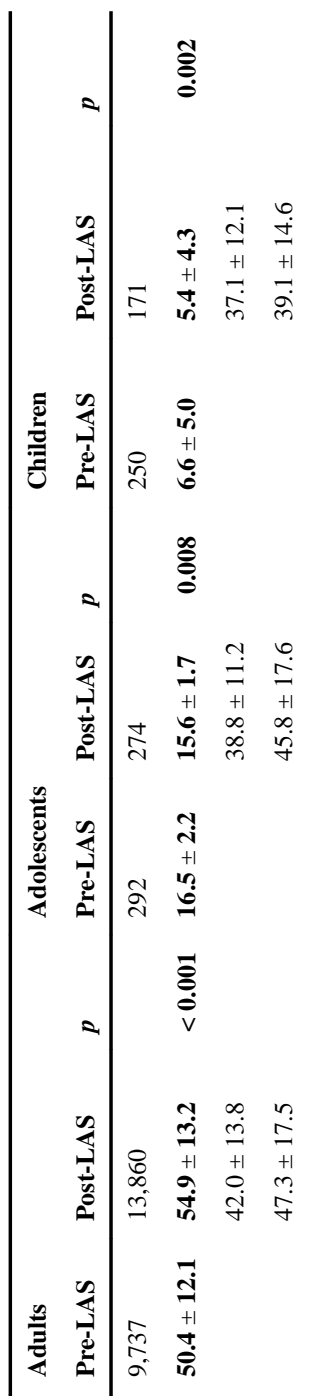

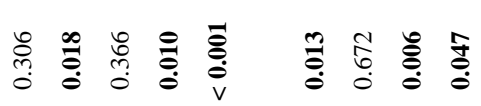

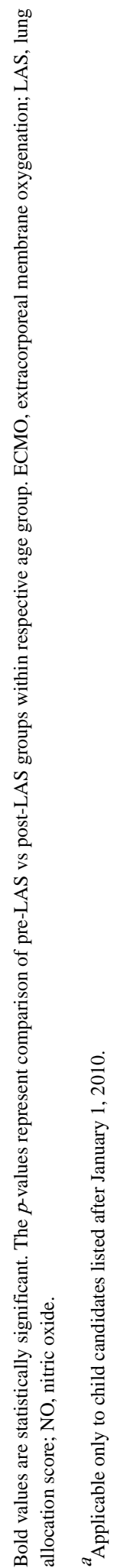

J Heart Lung Transplant. Author manuscript; available in PMC 2020 January 02. 